\title{
Successful implementation of general health policies in the Islamic Republic of Iran: barriers and mechanisms
}

Mohammad Meskarpour Amiri ${ }^{1,2}$ and Ali Mehrabi Tavana ${ }^{1}$

${ }^{1}$ Health Management Research Center, Baqiyatallah University of Medical Sciences, Tehran, Islamic Republic of Iran. ${ }^{2}$ Faculty of Management and Economics, Tarbiat Modares University, Tehran, Islamic Republic of Iran. (Correspondence to: Ali Mehrabi Tavana: Mehrab@bmsu.ac.ir).

\begin{abstract}
Background: The general health policies for the Islamic Republic of Iran were approved in April 2014.

Aims: This study examined the barriers currently faced by general health policies and the mechanisms required for the successful implementation of these polices.

Methods: This qualitative study was conducted as a two-phase project based on standard CAN-IMPLEMENT guidelines. A set of qualitative methods, including face-to-face in-depth interviews, focus groups, and in-person consensus meetings, were used to clarify mechanisms and barriers.

Results: Twenty-one mechanisms and 13 barriers were identified. The majority of mechanisms were related to the development of health infrastructures and appropriate allocation of resources. The most significant barriers to implementation of general health policies were lack of formulated strategies, poor management, lack of a comprehensive national action plan, minimal information infrastructures, and inadequate funding
\end{abstract}

Conclusions: A thorough understanding of barriers and mechanisms for implementation of general health policies can provide the necessary background to ensure successful health promotion in the country.

Keywords: Health policy, health systems, health plan implementation, Iran.

Received: 02/05/17; accepted: 13/11/17

Citation: Meskarpour Amiri M; Mehrabi Tavana A. Successful implementation of general health policies in the Islamic Republic of Iran: barriers and mechanisms. East Mediterr Health J. 2018;24(12):1127-1134. https://doi.org/10.26719/emhj.18.009

Copyright (C) World Health Organization (WHO) 2018. Some rights reserved. This work is available under the CC BY-NC-SA 3.0 IGO license (https:// creativecommons.org/licenses/by-nc-sa/3.o/igo).

\section{Introduction}

During the three last decades the health system in the Islamic Republic of Iran has experienced various reforms with many different challenges and successes. The first and foremost was the establishment of the National Health Network in 1983 (1). The National Health Network was progressive in its establishment of a primary health care network in the country, but the advantages were restricted to the level of primary health care only, and the country's medical care still suffered from a poor referral system $(2,3)$. Over the next two decades, the health system underwent several reforms including integration of health provision and medical education, universal medical insurance, hospital autonomy, and rural health insurance (2). In 2005, deficiencies in the National Health Network were addressed through the Family Physician Programme, which was implemented to improve the referral system through a gatekeeping mechanism, but despite the programme's achievements it is still far from ideal $(4,5)$.

The latest attempt to reform the health system saw the Ministry of Health and Medical Education (MoHME) apply a set of reforms in the health care system in 2014 titled 'Health Sector Evolution Plan'. The two main objectives of these reforms were to reduce direct expenditure for inpatients and improve the quality of care in governmental hospitals (6). However, the presence of some challenges - including lack of sustainable financing, neglect of primary and preventive health care, and disregard for patients in private hospitals - had a negative effect on the reform (2). Today, the Health Sector Evolution Plan still faces criticism (7-9).

More than three decades of health reforms in the Islamic Republic of Iran has shown that there is a state of chaos at the health policymaking level, where a number of health reforms were not successful due to the country's political upheavals $(2,5)$. To address this situation, the Supreme Leader of the Islamic Republic of Iran approved the general health policies for the country on 7 April, 2014 (10), which define the principles and aims of the country's health system (11). These policies include implementation mechanisms for quantitative and qualitative development of health insurance and sustainable health financing, as well as emphasizing the comprehensiveness of health and community contributions to health promotion. The general health policies also emphasize improving the quality and safety of services, establishing infrastructures for producing medical products and equipment, organizing healthcare demand, traditional medicine, and medical education (11,12).

Despite MoHME's responsibility for policy-making, planning, evaluating, and monitoring of general health policies, barriers faced and mechanisms required for successful implementation have not been properly specified. Therefore, there are concerns that required 
changes in the health system have not been addressed $(11,12)$. Hence, this study researched such barriers and mechanisms for general health policy implementation in the Islamic Republic of Iran.

\section{Methods}

This qualitative study was conducted in 2015. It was implemented as a two-phase project adapted from standard CAN-IMPLEMENT guidelines (13). Methods included face-to-face in-depth interviews, focus groups, and in-person consensus meetings to define mechanisms and barriers. The document under review in this study was the general health policies of the Islamic Republic of Iran, issued 7 April, 2014 (10).

Based on the CAN-IMPLEMENT guidelines (13), a series of semi-structured in-depth face-to-face interviews were conducted with health system administrators and top-level planners. These individuals were composed of presidents and deputies of medical sciences universities, health research centres, and health care centres. Each participant received a package including the general health policies document and a general format of the questions, and were asked to highlight important barriers and facilitator mechanisms for the implementation of general health policies. During the interview, snowball sampling was employed to identify additional participants until saturation. All the interviews were performed by two experienced interviewers in associated fields of study.

For data analysis, the thematic analysis was performed through the process of a coding framework as reported by Braun et al. (14) and used in previous studies $(15,16)$. The framework included six phases: familiarizing with data, generating initial codes, searching for themes among codes, reviewing themes, defining and naming themes, and producing the final report (14). Each interview was transcribed immediately after recording. After transcribing all interviews, the researchers reviewed the text several times until a general impression was received. Then a coding process was conducted for each interview manually by using constant comparative methods $(17,18)$. Thus, all texts were broken down into meaningful units and initial codes were obtained. Codes with similar meanings were grouped into subcategories; similar subcategories were grouped into main categories. The credibility of the categories was determined by using frequency of occurrence and consistency mentioned by participants in the interviews. The themes were discussed, defined and refined by research members repeatedly until no new themes were detected.

For the second step of study, three 90-minute inperson focus groups were formed with the presence of all participants. These focus groups were managed and recorded by a professor within a relevant research field and a research assistant. In the first two focus groups, the results of the previous interviews were revealed and the participants asked to discuss the barriers and implementation mechanisms of general health policies (elicited from the context of the interviews). In the third focus group, participants were asked to rate the importance of each proposed barrier and mechanism from one to ten on a Likert scale (8). The purpose of this third focus group was to rank the study results using RAND appropriateness (9) with regard to barriers and mechanisms consensus.

To ensure reliability within the study, face-to-face involvement with participants extended over long periods, with repeated sessions and feedback received from participants in order to minimize inaccuracies and maintain the trustworthiness of the study guaranteed through participants' confirmation, consensus meetings and related evidence.

\section{Results}

A total of 32 health system top-level managers and planners were interviewed face to face. More than $90 \%$ of participants were male with $\mathrm{PhD}$ degrees, half were in the age range of 50 to 60 years old, and $37 \%$ and $50 \%$ held the position of president/deputy of medical sciences universities or heads/deputies of health research centers, respectively. The remaining participants were chiefs or deputies of hospitals (Table 1).

During the interviews, all comments concerning mechanisms and barriers were collected and were identified at the level of health system policy-making and management. Majority of mechanisms were related to the development of health infrastructures (including family practitioner, referral system, health insurance system, electronic health records, etc.) as well as appropriate

\begin{tabular}{|c|c|c|}
\hline Variable & Number & $\%$ \\
\hline \multicolumn{3}{|l|}{ Sex } \\
\hline Male & 30 & 93.75 \\
\hline Female & 2 & 6.25 \\
\hline \multicolumn{3}{|l|}{ Age } \\
\hline $30-40$ & 5 & 15.63 \\
\hline $40-50$ & 6 & 18.75 \\
\hline $50-60$ & 15 & 46.88 \\
\hline $60-70$ & 5 & 15.63 \\
\hline$\geq 70$ & 1 & 3.13 \\
\hline \multicolumn{3}{|l|}{ Education level } \\
\hline MSc/M.D & 1 & 3.13 \\
\hline Ph.D & 31 & 96.88 \\
\hline \multicolumn{3}{|l|}{ Position } \\
\hline University director or deputy & 12 & 37.50 \\
\hline Research centre director or deputy & 16 & 50.00 \\
\hline Hospital director or deputy & 4 & 12.50 \\
\hline
\end{tabular}


allocation of resources within the health system (including attention to the needs of the health sector, targeted subsidies to promote health, and development financial controllers). When discussing a successful model for the Primary Health Care (PHC) network in the Islamic Republic of Iran, participants emphasized that establishment of health infrastructures can lead to major improvements in public health indicators. Furthermore, many participants acknowledged that having accurate and targeted allocation of resources within the health system is essential to fulfill national health needs and better achievement of general health policies. For example; regarding the family physician and referral system, one of the interviewees stated that:

"Proper implementation of a family physician plan facilitates access to an effective and efficient referral system and leads to the realization of many paragraphs within general health policies. For instance, in Paragraph 5 of the general health policies we can see the organization of demands, or even in Paragraphs 2-5 we can see the promotion of health indicators to the first ranking in the region. All of these require a comprehensive national plan for the development of a fundamental programme ... therefore, in my opinion, the implementation of a family physician plan is the cornerstone of the general health policies."

In terms of attention to general health policies in the formulation process of the country's five-year economic, social and cultural plans; one interviewee noted that:

"I have noted the general health policies document as one which determines to a great extent the dominant factor of activities in the health sector. To meet these goals, we need accurate and long-term planning ... we have had five-year economic, social, and cultural development plans for several decades in our country; however, we have overlooked health development and even there is no trace of health in naming development programmes. Our development plans should be one for economic, social, cultural, and health development. In my view, the general health policies do not have a suitable place in Iran's development plans.'

Another interviewee pointed out the importance of conducting applied research to meet national needs in the health sector as follows:

"Under the current conditions where our country is facing problems in terms of imports of medications and medical equipment, conducting applied research to deal with national needs has been doubled. Our experts and scientists have made broad progress in this field, which has led to the production of medications in the treatment of a number of incurable diseases such as hepatitis, multiple sclerosis, Alzheimer's and cancer; thus, the country does not need to import some of these medications anymore. Therefore, in my opinion, targeted allocation of resources for conducting applied research can support general health policies and a resistant economy."

Also in terms of the significant role of electronic health records, one interviewee commented that:

"Nowadays, having access to health data can contribute to providing health services in order to meet the basic health requirements for each person ... Of course, this does not end here, but electronic recording of medical histories can help not only in upgrading individual health, but also in reducing the costs of frequent diagnostic tests and medication transcriptions. Therefore, health promotion based on the professional and economic principles and consistent with general health policies depends on having electronic health records from birth to death."

In addition, one interviewee raised the following issues in terms of changing the role of the health insurance system:

"The issue of prevention before cure is the first and foremost paragraph in the general health policies. In my opinion, insurance companies should be the catalyst for changes in attitudes. Currently, insurance agencies in our country insure the illness and treatment but not the health and prevention. Prevention services and screenings do not have any place in our insurance packages. Most of those insured are not encouraged to take prevention activities such as weight control, blood pressure and so forth. Lots of important diseases are identified and treated in the final stage, which is usually costly and ineffective ... insurance companies should identify economic measures for cost-effective prevention and screening and make them mandatory for those groups at risk."

The results of the consensus meetings to rate the implementation mechanisms, based on a Likert scale (o-10), are illustrated in Table 2.

Barriers to implementing general health policies were elicited from individual interviews and focus groups as well as the results of ranking barriers in consensus meetings (Table 3). The most important barriers to the implementation of general health policies were lack of formulated strategies, poor management, lack of a comprehensive national action plan, minimal information infrastructures, and inadequate funding. Most of the interviewees argued that no definite and fixed strategies have been determined for the realization of general health policies and whenever senior management within the health system changes, different strategies are then established and followed. In this context, one of the interviewees reiterated that:

"Unfortunately, reforms were not pieces of a puzzle to solve a problem ... each government tries out their own procedures to meet the goals while the processes conducted by former governments remained unfinished. One government pays attention to the issue of family physician programmes, while the next government puts health sector evolution plans at the centre of attention."

Moreover, some interviewees believed there are not appropriate information infrastructures and financing for realization of general health policies. Regarding information for decision-making, one interviewee 


\section{Table 2 Ranking of proposed implementation mechanisms for general health policies}

Mechanisms

Mean rating Median Quarterfinal

$( \pm \mathrm{SD})$

1 Organizing the referral system through a family physician programme

$9.88( \pm 0.34) \quad 10 \quad 10$

Considering general health policies in formulation processes of 5-year economic, social, and

cultural plans

3 Allocation of grants to the national needs of health sector

$9.72( \pm 0.46) \quad 10 \quad 10$

4 Preparations for electronic health records

Covering the cost-effectiveness of screening and preventive activities by insurance organizations

6 Developing standards, protocols and clinical guidelines and necessary controls

7 Identify and managing hazards and environmental pollution of hospitals and clinical centres

8 Identify and introducing each person/household to the role of controlling and reducing healththreatening pollution

Construction of agricultural facilities to produce organic foods and cultivate medicinal plants at each medical sciences university

10 Holding international conferences to introduce Iranian traditional medicine

Establish prevention clinics in hospitals affiliated to the Ministry of Health and Medical

11 Education

Focus on economic evaluation and health technology assessment in the process of purchasing, manufacturing and even researching high-tech medicines and medical equipment

13 Subsidizing the consumption of healthy food (targeted subsidies to promote health) Food fortification with micronutrients based on geographical distribution of micronutrient

4 and vitamin deficiencies in the Islamic Republic of Iran

Establishing clinics of traditional medicine in the hospitals affiliated to the Ministry of Health

15 and Medical Education

Offering financial incentives by insurance companies to maintain health through risk

16 reduction and lifestyle promotion

Qualitative and quantitative progress in the education of academic traditional medicine and traditional pharmacy at universities

18 Equitable needs-based increase in the number of health care centres in the cities and provinces

19 Financial support for documentation of traditional medicine

$9.72( \pm 0.46) \quad 10 \quad 10$

$9.63( \pm 0.49) \quad 10 \quad 10$

$9.50( \pm 0.51) \quad 9.5 \quad 10$

$9.38( \pm 0.49) \quad 9 \quad 10$

$9.19( \pm 0.59) \quad 9 \quad 10$

$9.00( \pm 0.62) \quad 9$

$8.97( \pm 1.18) \quad 9.5 \quad 10$

$8.69( \pm 1.26) \quad 9 \quad 10$

$8.44( \pm 1.37) \quad 8 \quad 10$

$8.06( \pm 1.44) \quad 8 \quad 9.5$

$7.94( \pm 1.44) \quad 8 \quad 9$

$7.75( \pm 1.39) \quad 8 \quad 9$

$7.59( \pm 1.21) \quad 7 \quad 8$

$7.47( \pm 1.16) \quad 7 \quad 8$

$7.28( \pm 1.08) \quad 7 \quad 8$

$7.19( \pm 0.64) \quad 7 \quad 8$

$7.09( \pm 0.59) \quad 7 \quad 7$

$7.06( \pm 0.67) \quad 7$

20 Identifying and introducing healthy and unhealthy foods at the community level

Formulation of suitable financial controls for patients and doctors, in order to avoid excessive demands on the health care system

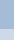

0

.5

9

9

8

8


stated that, "Most of our decisions are made based on speculations and guesswork, not based on reliable data and evidence ... sometimes we are not even able to screen or observe the results of our enforced policy." In addition, in terms of financing health systems, most of the interviewees pointed to issues such as instability in financing the health sector evolution plan (HSEP), changes in income and the annual government budget, as well as the health-care sector's share of GDP.

According to findings, general health policies might not necessarily be accepted or attempted by policymakers due to conflicts of interests among certain stakeholders. For example, one of the interviewees with medical specialism clearly expressed opposition to the promotion of traditional medicine, stating that, "Today, some claim that they can heal bedsores through traditional medicine. However, as a surgeon I reject this issue. I even had patients using traditional methods who were referred to me with severe conditions. Traditional medicine has been abused and has become an excuse for fraud."

\section{Discussion}

This study was implemented immediately after notification of the country's general health policies by the Supreme Leader. According to the results, organizing the referral system through the Family Physician Programme was the first and foremost mechanism for successful implementation of general health policies in the Islamic Republic of Iran. The availability capacity of family physicians for developing the country's referral health system has already been mentioned in previous studies $(19,20)$. Although the Family Physician Programme has been termed the second health reform revolution (3), there is still not sufficient effort made to implement it across the country. Despite the significant and positive effects of the Family Physician Programme on health indicators (21), the programme is still far from ideal when it comes to universal coverage. Policy-makers need to develop the Family Physician Programme as one of the most important mechanisms for realizing Iranian macro-health policies.

Lack of agreed health policy-making and planning has always been one of the most important challenges for the Iranian health system (22). According to our study results, attention to general health policies in formulation processes of five-year development plans is necessary for the successful implementation of general health policies. The country's 5-year development plans (5YDP) are strategic and operational plans designed at national level for managing the nation's economic, social and cultural development. Five development plans have been prepared and implemented since 1979; among them the 5th 5YDP is noted for targeting the country's health system development (11). However, according to our study results 5 YDPs have good capacity to visualize and actualize the nation's general health policies and to overcome current and future health challenges. However, its implementation needs active leaders, capable managers, motivated technical staff and social mobilization (11).

The issue of setting up an efficient electronic health record was recognized as one of the most important mechanisms for implementing general health policies. However, lack of necessary information infrastructures for evidence-based decision-making was elicited as one of the most important barriers to implementing general health policies. In this regard, Mehrdad (23) in his study stated that the lack of integrated health information systems in the Iranian health sector limits the possibility of health systems performance analysis. In addition, Larijani et al. (22) emphasized the need for more attention given to an evidence-based policy-making process in Iran health system, yet data base infrastructures are still not completely operational in the country. This was clearly seen in the transcribed interviews in the present study. However, it should be noted that in the past few years MoHME has made great progress in electronic health record creation, particularly in out-patient services (24).

Inadequate and unstable financing in the health system is another barrier to successful implementation of general health policies. These include limited and unsustainability of financial resources and an imbalance between resources and expected services $(11,25)$. Such financial issues make it difficult to define healthcare objectives for health reforms (26) and many health reforms have begun to falter due to a lack of sustainable financing. The most recent example was the Health Sector Evolution Plan (HSEP) (27), which received extensive reaction in official and social media, but concerns raised about the economic burden of the programme on public finances meant it was viewed as unviable.

In such situations a rigorous economic analysis of the priorities and trade-offs inherent in the system would help health policy-makers to confront financial challenges and to achieve their desired objectives more effectively (26). Unfortunately the lack of prioritization for healthcare reforms at the national level was identified as one of the major barriers to the implementation of the general health policies. Asadi et al. (28) mentioned in their study the achievements of the primary health care ( $\mathrm{PHC}$ ) system in the Islamic Republic of Iran and considered needs analysis and prioritization of health reforms essential for the improvement of PHC performance. Similarly, the World Bank also acknowledged the Iranian PHC system and argued that its performance should be prioritized based on new needs analyses in order to make structural reforms. This would be required for upcoming health needs and priorities in the country, including changes in the patterns of disease and an ageing population (29). The latest HSEP has invested new financial resources in therapeutic and hospital services; however, some experts believed that any reforms should be started by PHC and the preventative medicine sector. Although many efforts have been made to develop PHC as part of HSEP, the plan has still been criticized for not considering the primacy of PHC and preventive programmes $(27,30)$.

Finally, the issues raised by the interviewees and the empirical evidence cited suggest that general health 
policies might not be necessarily accepted and attempted by policy-makers due to conflict of interests among certain stakeholders, which was also emphasized by the Health Policy Council of MoHME (11). Policy-making, pricing, provision and monitoring are done by medical doctors simultaneously in the country's health system, which could create conflict of interests for policy-making and greatly harm the principle of impartiality. Ellen et al. (31) stated conflict of interests as a general reason for negative attitudes and resistance to change and identified it as the most important barrier to evidence-based decision-making in Canada's health system. Likewise, findings by Wye et al. (32) indicate that many health policy-makers in the British health system are concerned about their personal interests and benefits. Therefore, attention to policy-makers' priorities and development of mutual interests remain influential for successful implementation of health policies and plans.

\section{Limitations}

The first limitation to this study was that due to the expansion of general health policies, many of the paragraphs remained without any comment. Future studies should categorize general health policies and have a detailed paragraph by paragraph review. The second limitation was the selection of interviewees only from the Iranian health-care system of Iran, since general health policies address all organizations and systems relevant to health. Finally, we would like to reemphasize that this study only highlights a number of the most important barriers and mechanisms necessary for successful implementation of the general health policies; further studies may identify still more barriers and mechanisms.

\section{Conclusion}

The general health policies have created a great capacity for quantitative and qualitative health promotion in the Islamic Republic of Iran. Correct implementation could lead to a revolution in health services in Iranian society, which itself can be a model for health promotion in lowincome countries. A better understanding of barriers and mechanisms to the successful implementation of general health policies would provide the necessary background to support the current potential for health promotion. Finally, we suggest that the application of general health policies must be evaluated by health policy-makers every five years at least.

\section{Acknowledgements:}

We would like to express our gratitude to all those who assisted us during the course of this research.

Funding: None.

Competing interests: None declared.

\section{Mise en œuvre réussie des politiques générales de santé en République islamique d'Iran : mécanismes et barrières}

\section{Résumé}

Contexte : Les politiques générales de santé de la République islamique d'Iran ont été approuvées en avril 2014 .

Objectif : La présente étude a examiné les barrières auxquelles se heurtent actuellement les politiques générales de santé, ainsi que les mécanismes requis pour assurer le succès de leur mise en œuvre.

Méthodes : Il s'agissait d'une étude qualitative menée dans le cadre d'un projet en deux phases reposant sur les directives CAN-IMPLEMENT ${ }^{\odot}$. Un ensemble de méthodes qualitatives, incluant des entretiens approfondis en face-à-face, des groupes de discussion et des réunions de consensus, ont été utilisées afin de déterminer les mécanismes et les barrières à ce sujet.

Résultats : Vingt et un mécanismes et treize barrières ont été identifiés. Dans leur majorité, les mécanismes étaient liés à la mise en place d'infrastructures de santé et à une allocation adéquate des ressources. Les barrières les plus significatives à la mise en œuvre des politiques générales de santé étaient un manque de stratégies efficaces, une mauvaise gestion, l'absence de plan d'action national complet, des infrastructures d'information limitées, et un financement insuffisant.

Conclusion : Une compréhension approfondie des barrières et des mécanismes pour la mise en œuvre des politiques générales de santé peut fournir le contexte nécessaire afin d'assurer une promotion de la santé réussie dans le pays.

$$
\begin{aligned}
& \text { آليات التنفيذ الناجح للسياسات الصحية العامة في جمهورية إيران الإسلامية والعوائق أمام ذلك } \\
& \text { محمد مسكربور-أميري، علي مهرابي-توانا } \\
& \text { الخلاصة }
\end{aligned}
$$

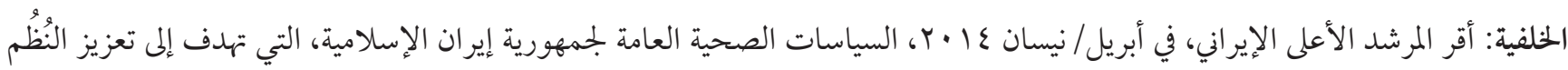

$$
\begin{aligned}
& \text { الصحية في القطر. }
\end{aligned}
$$


الأهداف: تهدف هذه الدراسة البحثية إلى تحديد وفحص آليات التنفيذ الناجح للسياسات الصحية العامة والعوائق التي قد تقف أمام ذلك.

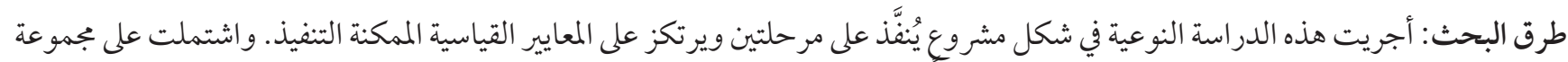

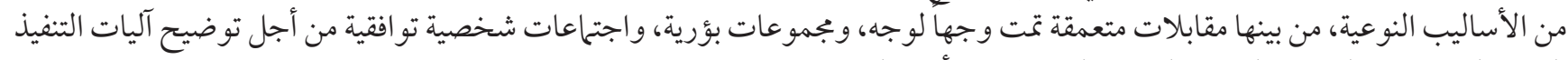

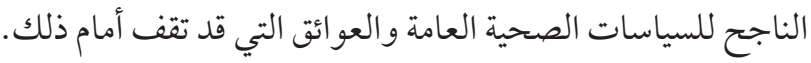

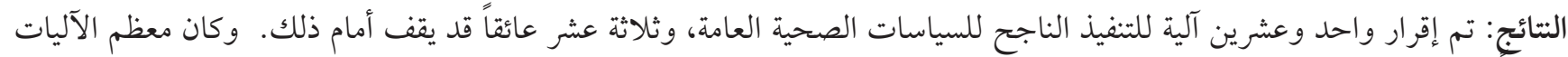

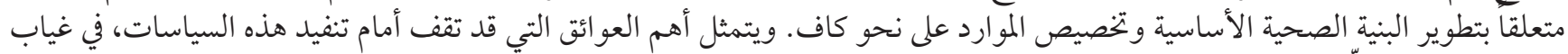

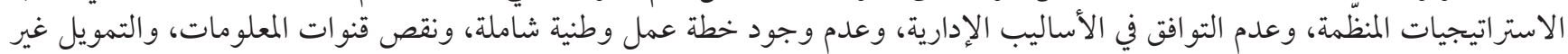
الكافي.

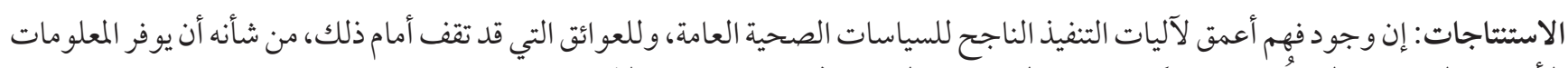

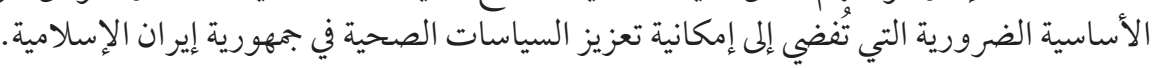

\section{References}

1. Shadpour K. Primary health care networks in the Islamic Republic of Iran. East Mediterr Health J. 2000 Jul;6(4):822-5. PMID:11794090

2. Heshmati B, Joulaei H. Iran's health-care system in transition. Lancet. 2016 Jan 2;387(10013):29-30. https://doi.org/10.1016/So1406736(15)01297-o PMID:26766344

3. Takian A, Rashidian A, Kabir MJ. Expediency and coincidence in re-engineering a health system: an interpretive approach to formation of family medicine in Iran. Health Policy Plan. 2011 Mar;26(2):163-73. https://doi.org/10.1093/heapol/czq036 PMID:20732859

4. Takian A, Doshmangir L, Rashidian A. Implementing family physician programme in rural Iran: exploring the role of an existing primary health care network. Fam Pract. 2013 Oct;30(5):551-9. https://doi.org/10.1093/fampra/cmt025 PMID:23788202

5. Esmaeili R, Hadian M, Rashidian A, Shariati M, Ghaderi H. Family medicine in Iran: facing the health system challenges. Glob J Health Sci. 201411 30;7(3):260-6. https://doi.org/10.5539/gjhs.v7n3p260 PMID:25948450

6. Moradi-Lakeh M, Vosoogh-Moghaddam A. Health sector evolution plan in Iran; equity and sustainability concerns. Int J Health Policy Manag. 201508 31;4(10):637-40. https://doi.org/10.15171/ijhpm.2015.160 PMID:26673172

7. Piroozi B, Rashidian A, Moradi G, Takian A, Ghasri H, Ghadimi T. Out-of-Pocket and Informal Payment Before and After the Health Transformation Plan in Iran: Evidence from Hospitals Located in Kurdistan, Iran. Int J Health Policy Manag. 201702 11;6(10):573-86. https://doi.org/10.15171/ijhpm.2017.16 PMID:28949473

8. Hashemi B, Baratloo A, Forouzafar MM, Motamedi M, Tarkhorani M. Patient satisfaction before and after executing health sector evolution plan. Iranian Journal of Emergency Medicine. 2015;2(3):127-33.

9. Meskarpour-Amiri M, Assari-Arani A, Sadeghi H, Agheli-Kohnehshahri L. Socioeconomic Factors Affecting Informal Payments in the Health Sector. Transylv Rev Adm Sci. 2016;12(47):116-28. https://rtsa.ro/tras/index.php/tras/article/view/475.

10. Marandi SA. The Health Landscape of the Islamic Republic of Iran. Medical Journal of Islamic World Academy of Sciences. 2016;24(2):56-64.

11. Vosoogh Moghaddam A, Damari B, Alikhani S, Salarianzedeh M, Rostamigooran N, Delavari A, et al. Health in the 5th 5-years Development Plan of Iran: main challenges, general policies and strategies. Iran J Public Health. 2013 01 1;42(1) Supple1:42-9. PMID:23865015

12. Tavana AM, Amiri MM. New view on health policies of the Islamic Republic of Iran: Health system reform. Ann Trop Med Public Health. 2017;10:767-8. 10.4103/1755-6783.188524

13. Harrison MB, Graham ID, van den Hoek J, Dogherty EJ, Carley ME, Angus V. Guideline adaptation and implementation planning: a prospective observational study. Implement Sci. 2013 05 8;8(1):49. https://doi.org/10.1186/1748-5908-8-49 PMID:23656884

14. Braun V, Clarke V. Using thematic analysis in psychology. Qual Res Psychol. 2006;3(2):77-101. https://doi. org/10.1191/1478088706qpo63oa

15. Iravani M, Janghorbani M, Zarean E, Bahrami M. Barriers to Implementing Evidence-Based Intrapartum Care: A Descriptive Exploratory Qualitative Study. Iran Red Crescent Med J. 2016 o1 1;18(2):e21471. https://doi.org/10.5812/ircmj.21471 PMID:27175303

16. Cabana MD, Rand CS, Powe NR, Wu AW, Wilson MH, Abboud P-AC, et al. Why don't physicians follow clinical practice guidelines? A framework for improvement. JAMA. 1999 Oct 20;282(15):1458-65. https://doi.org/10.1001/jama.282.15.1458 PMID:10535437

17. Vander Putten J, Nolen AL. Comparing results from constant comparative and computer software methods: A reflection about qualitative data analysis. J Ethnogr Qual Res. 2010;5(1):99-112. 10.2139/ssrn.1752577

18. Boeije H. A purposeful approach to the constant comparative method in the analysis of qualitative interviews. Qual Quant. 2002;36(4):391-409. https://doi.org/10.1023/A:1020909529486

19. Yazdani S, Akbari Lakeh M. Which Health Cares Are Related to the Family Physician? A Critical Interpretive Synthesis of Literature. Iran J Public Health. 2017 May;46(5):585-90. PMID:28560187 
20. Khayatzadeh-Mahani A, Takian A. Family physician program in Iran: considerations for adapting the policy in urban settings. Archives of Iranian medicine. 2014;17(11):776-8. DOI: 0141711/AIM.0012

21. Naderimagham S, Jamshidi H, Khajavi A, Pishgar F, Ardam A, Larijani B, et al. Impact of rural family physician program on child mortality rates in Iran: a time-series study. Popul Health Metr. 201706 2;15(1):21. https://doi.org/10.1186/s12963-017-0138-0 PMID:28576122

22. Larijani B, Delavari A, Damari B, Moghadam AV, Majdzadeh R. Health policy making system in Islamic Republic of Iran: review an experience. Iran J Public Health. 2009;38 Suppl. 1:1-3.

23. Mehrdad R. Health system in Iran. Japan Med Assoc J. 2009;52(1):69-73.

24. Ahmadi M, Foozonkhah S, Shahmoradi L, Mahmodabadi AD. Messaging standard requirements for electronic health records in Islamic Republic of Iran: a Delphi study. East Mediterr Health J. 201602 1;22(11):794-801. https://doi.org/10.26719/2016.22.11.794 PMID:28177109

25. Lankarani KB, Alavian SM, Peymani P. Health in the Islamic Republic of Iran, challenges and progresses. Med J Islam Repub Iran. 2013 Feb;27(1):42-9. [MJIRI] PMID:23479501

26. Davari M, Haycox A, Walley T. Health care financing in iran; is privatization a good solution? Iran J Public Health. 2012;41(7):1423. PMID:23113205

27. Moradi-Lakeh M, Vosoogh-Moghaddam A. Health Sector Evolution Plan in Iran; equity and sustainability concerns. Int J Health Policy Manag. 201508 31;4(10):637-40. https://doi.org/10.15171/ijhpm.2015.160 PMID:26673172

28. Asadi-Lari M, Sayyari AA, Akbari ME, Gray D. Public health improvement in Iran-lessons from the last 20 years. Public Health. 2004 Sep;118(6):395-402. https://doi.org/10.1016/j.puhe.2004.05.011 PMID:15313592

29. Gressani D, Saba J, Fetini H, Rutkowski M, Maeda A, Langenbrunner J. Islamic Republic of Iran health sector review: main report. Washington, DC: World Bank, 200839970 - IR Contract No.: 39970 - IR.

30. Piroozi B, Moradi G, Nouri B, Mohamadi Bolbanabad A, Safari H. Catastrophic health expenditure after the implementation of health sector evolution plan: a case study in the west of Iran. Int J Health Policy Manag. 201603 14;5(7):417-23. https://doi. org/10.15171/ijhpm.2016.31 PMID:27694669

31. Ellen ME, Léon G, Bouchard G, Ouimet M, Grimshaw JM, Lavis JN. Barriers, facilitators and views about next steps to implementing supports for evidence-informed decision-making in health systems: a qualitative study. Implement Sci. 201412 5;9(1):179-91. https://doi.org/10.1186/s13012-014-0179-8 PMID:25476735

32. Wye L, Brangan E, Cameron A, Gabbay J, Klein JH, Pope C. Evidence based policy making and the 'art' of commissioning - how English healthcare commissioners access and use information and academic research in 'real life' decision-making: an empirical qualitative study. BMC Health Serv Res. 201509 29;15(1):430-42. https://doi.org/10.1186/s12913-015-1091-x PMID:26416368 